\title{
A Comparison of Rhetorical Moves in Students' Undergraduate Thesis Abstracts
}

\author{
Mochammad Rizki Juanda*, Eri Kurniawan \\ English Education Department, Universitas Pendidikan Indonesia, Bandung, Indonesia \\ *Corresponding author. Email: eri_kurniawan@upi.edu
}

\begin{abstract}
Research on rhetorical move in abstracts has received attention in recent years. Different disciplines employ different strategies in manifesting rhetorical move in their writing. However, cross-disciplinary studies on rhetorical move in abstract still need to be done to examine the similarities and differences of the realization of rhetorical moves between different disciplines. This study aims to identify the manifestation of rhetorical move used in the undergraduate thesis abstracts written by Natural Science and Social Science students in a university in Bandung, Indonesia. A total of 120 abstracts were taken from six disciplines (20 abstracts each) i.e. Mathematics, Chemistry, Physics, Geography, Sociology, and History. Hyland's (2004) model was used as the guideline for the analysis and the AntMover software was used to assist the analysis. The result showed that Natural Science and Social Science employed different strategies in realizing the moves. Introduction, Methodology, and Findings were the most manifested move in Natural Science, while Introduction, Purpose, Methodology, and Findings were the most manifested move in Social Science. The findings also showed that both Natural Science and Social Science employ different strategies in realizing some steps in a certain move. In conclusion, the nature of the disciplines does affect the manifestation of rhetorical moves in undergraduate thesis abstracts. This study provides an insight into the trend of rhetorical move patterns in both Natural Science and Social Science undergraduate thesis. Some recommendations have been provided as an insight concerning the trend of rhetorical move both Natural Science and Social Science undergraduate theses.
\end{abstract}

Keywords: Disciplinary variation, move analysis, rhetorical move, undergraduate thesis abstract

\section{INTRODUCTION}

In academic contexts, writing has remained a great challenge for academic writers especially novice students. Besides, the use of English has increased the complexities of writing for EFL students (Fatma \& Yağiz, 2020; Pasavoravate, 2011). Regarding this problem, scholars employ genre analysis to uncover the rhetorical structure of academic writing explicitly (Marefat \& Mohammadzadeh, 2013). Therefore, there has been a growing number of interests in this topic in order to produce a better type of academic and scientific texts for teaching models.

In line with the growing number of academic texts, genre-based approach on rhetorical structure of Research Article (RA) abstracts have become significantly important since abstracts are not a part of the research article genre but it is another genre (Bhatti, Mustafa, \& Azher, 2019). It also assists readers to quickly determine the relevancy of the abstract to their interest (Kurniawan et al., 2019). Thus, an abstract is one of the important factors in determining whether a work should be read further or not (Fatma \& Yağiz, 2020; Kurniawan et al., 2019; Suryani \& Rismiyanto, 2019). Moreover, it also gives readers a summary of the work to grasp the important point of the work easier (Nasseri \& Nematollahi, 2014).

Following the importance of abstracts, numerous studies have been conducted on the topic. Some research focused on comparing abstract across disciplines (Afshar, Doosti, \& Movassagh, 2018; Bhatti et al., 2019; Elhambakhsh, Jalilifar, \& White, 2018), some studies identify the difference of language used (Hirano, 2009; Pasavoravate, 2011), and some studies highlighted works from different authors across different academic level (Ren \& Li, 2011; Suryani \& Rismiyanto, 2019). Based on the recent studies, the current trend of studies on rhetorical structure of abstracts focus on the comparative studies (Fatma \& Yağiz, 2020). 
Thus, research on abstract across discipline is still important. Besides, the different experience in writing of students from different disciplines is interesting to be observed. Furthermore, most recent studies focused on abstracts of research article, master thesis and dissertation while research on undergraduate thesis abstract is limited in number (Suryani \& Rismiyanto, 2019). One of the factors to this phenomenon may due to student's lack of experience in conducting academic research since they are still regarded as novice in the academic community (Male, 2018). Moreover, Indonesian authors tend to use inappropriate rhetorical move in their writing (Arsyad \& Arono, 2016). Most of the Indonesian authors did not follow the manuscript from the International editor in writing their article that lead to rejection (Adnan, 2009). On the other hand, writing an article that deprived from their thesis is one of the requirements for bachelor student in taking its degree. As a result, it is necessary for students to use the appropriate structure of their article since the article will reflect the content of their thesis. Therefore, this study aimed to do a genre-based comparative study on Natural Science and Social Science abstracts of a university in Bandung, Indonesia. Hyland's Five-move analysis (2004) was the main framework for this study. This study sought to identify the moves and steps employed by Natural Science and Social Science students in their thesis abstracts.

\section{METHODS}

This qualitative study used move analysis and descriptive comparative approach since move analysis has become a framework for examining crossdisciplinary (Basturkmen, 2012; Cotos, Huffman, \& Link, 2017; Holmes, 1997) and cross-cultural variation (Wirada, 2012; ElMalik \& Nesi, 2008; Loi \& Evans, 2010; Yakhontova, 2006) in the various rhetorical structure of RA sections. This study sought to identify the moves and steps manifestation in the undergraduate thesis abstracts of Natural Science (Mathematics, Chemistry, and Physics) and Social Science (Geography, History, and Sociology) from Universitas Pendidikan Indonesia. After doing the comparative analysis, the results were displayed in the forms of tables and figures.

This study selected a total of 120 abstracts from Universitas Pendidikan Indonesia repository website which taken from Mathematics, Chemistry, Physics, Geography, History, and Sociology. A four year range from 2016-2019 are taken into consideration to ensure the validity of the data. This study used random sampling technique to collect the data by prioritizing the data from the recent year to the old one.

For the analysis, this study employed Ant Mover software to assist the process of analyzing the structure of the abstracts (Anthony, 2003). However, the software needs some training data so a corpus consisted of 30 abstracts were taken and inserted as the training for the software. The corpus for the data training was taken from two highly regarded university online repository, namely: (1) The University of Michigan Corpus of Upper Level Paper (MICUSP), and (2) Stanford Online Library. Researcher chose those two libraries because both of them are known as one of the leading universities in the world that listed in the top 200 universities in World University Ranking ("QS World University Rankings", 2020). The available abstracts were also written by upper level students and had gone through a thorough review process. The range of publication was from 2016-2019 so that the selected data had similar characteristics to the main data. For the analysis used AntMover 1.10, all abstracts were converted into .txt files because the software only accepted this format.

Table 1. Hyland's (2004) Model of Rhetorical Moves in RA

\begin{tabular}{|l|c|l|}
\hline \multicolumn{1}{|c|}{ Move } & Step & \multicolumn{1}{c|}{ Label } \\
\hline \multirow{4}{*}{ Introduction (I) } & 1 & Arguing for topic significance \\
\cline { 2 - 3 } & 2 & Making topic generalizations \\
\cline { 2 - 3 } & 3 & Defining the key term(s) \\
\cline { 2 - 3 } & 4 & Identifying gap \\
\hline Purpose (P) & 5 & Stating the research purpose \\
\hline \multirow{4}{*}{ Method (M) } & 6 & $\begin{array}{l}\text { Describing participants/data } \\
\text { source }\end{array}$ \\
\cline { 2 - 3 } & 7 & Describing instrument(s) \\
\hline Product (Pr) & 8 & $\begin{array}{l}\text { Describing procedure } \\
\text { context }\end{array}$ \\
\hline \multirow{4}{*}{ Conclusion (C) } & 9 & Describing the main results \\
\cline { 2 - 3 } & 10 & Deducing conclusion \\
\cline { 2 - 3 } & 11 & $\begin{array}{l}\text { Evaluating the significance of } \\
\text { the research }\end{array}$ \\
\cline { 2 - 3 } & 12 & $\begin{array}{l}\text { Stating limitations } \\
\text { implication }\end{array}$ \\
\hline
\end{tabular}

As seen in Table 1, in the Hyland's (2004) model, Move 1 - Introduction establishes context of the paper and motives for the research or discussion; Move 2 Purpose indicates purpose and outline the intention behind the paper; Move 3 - Method provides information on design, procedures, assumption, approach, and data; Move 4 - Product states the main findings and the arguments; and Move 5 - Conclusion interprets or extends results beyond scope of the paper, draws inferences, points to applications or wider implications. The procedure started by converting the entire abstracts into.txt format/Notepad-version document (Lubis, 2018). Then, the researcher inputted the data for analysis into AntMover 1.10. The software would automatically classify and mark the step for each 
sentence from the text which had been segmented by the software. However, the results of the analysis still needed to be re-verified to ensure that the sentence had been marked in the correct category. As there was a possibility of embedded moves and steps in the abstracts, this study took clauses and phrases as the unit analysis (Kafes, 2012, as cited in Kurniawan et al., 2019) to acquire more thorough results of move realization. Next, the researcher tabulated the data into Microsoft Excel. Then, the tabulated data was sorted based on each move and its constituent step. After that, the tense, voice and verbs were examined. Lastly, the researcher wrote the conclusion and discussion from the findings of the study.

\section{FINDINGS AND DISCUSSION}

Based on the analysis, this study found that all of the moves were included in the abstracts i.e. Move 1Introduction, Move 2- Purpose, Move 3- Method, Move 4- Findings and Move 5- Conclusion. A total of 588 moves were found in Natural Science studies and 582 moves in Social Science studies. Moreover, Move 4 was the most manifested move with a total of 350 occurrences across all of the disciplines. Figure 4.1 illustrated the occurrences of Move 1 - Move 5 across disciplines.

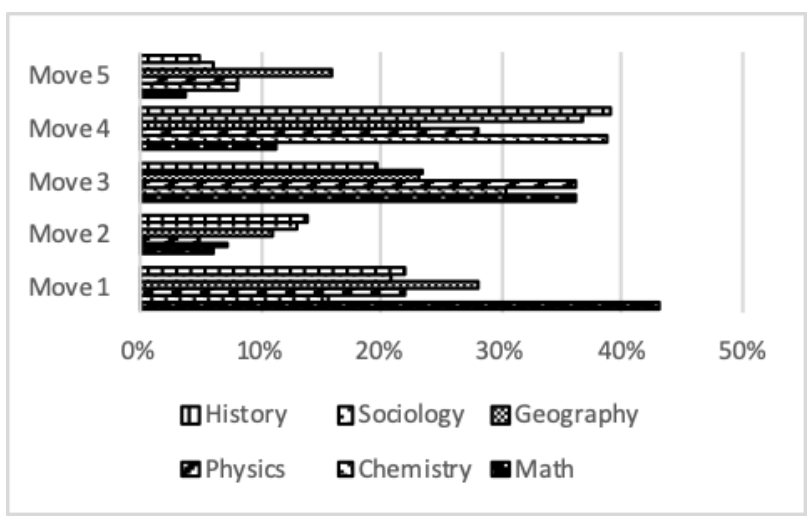

Figure 1 Move occurrences across all disciplines.

Based on Figure 1, Move 4 had the highest occurrences from the total number of the move since its' appearance dominated three disciplines i.e. Chemistry, Sociology, and History. It also appeared frequently in Physics and Geography, while appeared less in Mathematics. On the other hand, the findings of Move 3 and Move 1 showed almost similar results. Meanwhile, Move 2 and Move 5 were the less frequent move appeared compared to the other three moves. The high occurrences of Move 4 indicated that the authors attempt to explain the contribution of their study by highlighting the findings. By emphasizing the findings of the study, the authors tried to show the novel contribution of their studies since they are confident about the result of their research (El-Dakhs, 2018). On the other hand, some abstracts also applied mixed moves in their writing. Most of the findings showed that Move 1 was embedded in Move 2, and Move 3 was embedded in Move 4.

In the following paragraph, the occurrences of each step from each move are discussed. Move 2 and Move 4 do not be further analyze since both moves do not have any steps. Figure 4.2 shows the manifestation of steps of Move 1, Move 3, and Move 5.

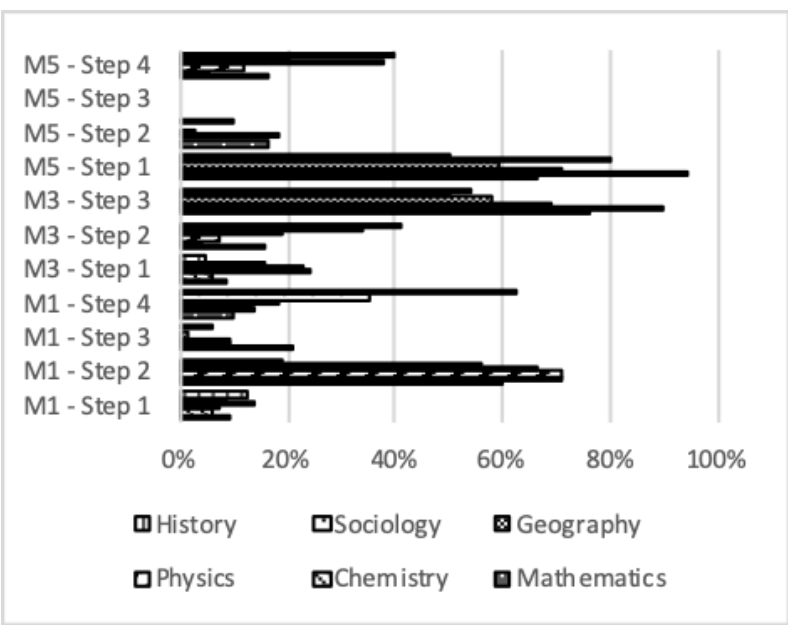

Figure 2 Steps occurrences across all disciplines.

Based on Figure 2, the similarities showed that Step 3 of Move 1- Defining the key term(s) was the least manifested step, while Step 1 of Move 5- Deducing conclusion was the most occurred step in the abstracts. Moreover, Step 3 of Move 5- Stating limitations did not appear in any abstracts. The absence of this step may occur due to the differences of the nature of the data. This step was not expected to occur in undergraduate thesis abstracts because this step usually occurred in an academic journal article of an expert writer and the appearance of this step was also considered rare even in academic journal article (Kurniawan et al., 2019). Regarding the differences, it showed that Step 2 of Move 3- Describing instrument(s), Step 4 of Move 1Identifying gap, and Step 4 of Move 5- Presenting recommendation or implication manifested more in Social Science while Step 3 of Move 3- Describing procedure and context(s) and Step 3 of Move 1Defining the key term(s) occurred more in Natural Science. The findings also found some mixed steps in the realization of the steps especially in Move 3.

The findings indicate that disciplinary variations affect the occurrences of typical steps in bachelor thesis abstracts such as the use of Step 4 of Move 1 as the way to show the main focus of the present study that differentiate it from other studies with similar topics and Step 4 of Move 5 as an insight from the author of the study for other researcher that is interested in conducting research with similar topic. By utilizing different steps in their abstracts, authors can point out 
different important points of their abstracts in attracting the readers.

Regarding the salience, this study employed Kanoksilapatham's categorization (2005) where the moves are considered optional if there are less than $66 \%$ occurrences, conventional if there are $=1>66 \%-99 \%$ occurrences, and obligatory if there are $100 \%$ occurrences in the abstracts. Kanoksilapatham's (2005) categorization was perceived more illustrative compared to Dos Santos' (1996), which only described obligatory (at least $80 \%$ of appearance) and optional categories.

Table 2 shows the status of the moves and steps. Move 1 was conventional in both fields where Natural Science attained $87 \%$ occurrences and Social Science achieved $95 \%$ occurrences. In contrast, Move 2 was optional $(60 \%)$ in Natural Science but was conventional $(95 \%)$ in Social Science. Meanwhile, despite the differences between the fields, Move 3 was considered obligatory in both Natural Science and Social Science. Move 4 was conventional in both fields where Natural Science attained $83 \%$ occurrences and Social Science achieved $93 \%$ occurrences. Move 5 was optional in both fields with $43 \%$ in Natural Science and $48 \%$ in Social Science.

Table 2. Move-Step Salience

\begin{tabular}{|c|c|c|c|c|c|}
\hline Move & $\begin{array}{l}\text { Natural } \\
\text { Science }\end{array}$ & $\begin{array}{c}\text { Social } \\
\text { Science }\end{array}$ & Step & $\begin{array}{l}\text { Natural } \\
\text { Science }\end{array}$ & $\begin{array}{c}\text { Social } \\
\text { Science }\end{array}$ \\
\hline \multirow{4}{*}{1} & \multirow{4}{*}{$87 \%$} & \multirow{4}{*}{$95 \%$} & 1 & $22 \%$ & $19 \%$ \\
\hline & & & 2 & $79 \%$ & $54 \%$ \\
\hline & & & 3 & $32 \%$ & $4 \%$ \\
\hline & & & 4 & $29 \%$ & $75 \%$ \\
\hline 2 & $60 \%$ & $95 \%$ & \multicolumn{3}{|c|}{ N/A } \\
\hline \multirow{3}{*}{3} & \multirow{3}{*}{$98 \%$} & \multirow{3}{*}{$98 \%$} & 1 & $34 \%$ & $31 \%$ \\
\hline & & & 2 & $29 \%$ & $46 \%$ \\
\hline & & & 3 & $97 \%$ & $97 \%$ \\
\hline 4 & $83 \%$ & $93 \%$ & & N/A & \\
\hline \multirow{4}{*}{5} & \multirow{4}{*}{$43 \%$} & \multirow{4}{*}{$48 \%$} & 1 & $79 \%$ & $71 \%$ \\
\hline & & & 2 & $21 \%$ & $7 \%$ \\
\hline & & & 3 & $0 \%$ & $0 \%$ \\
\hline & & & 4 & $14 \%$ & $54 \%$ \\
\hline
\end{tabular}

Move 1 was necessary since it was conventional and obligatory across the six disciplines. Meanwhile, the occurrences of Move 2 were high in the Social Science disciplines since all of the three disciplines shown the result of $=/>90 \%$ occurrences in its Move 2 - Purpose. Along with the diversity of topics in the Social Science disciplines, the authors of Social Science discipline attempted to emphasize the focus of their study by stating the general/specific purposes of the research. Move 4, in the previous discussion, was the most move that occurred across all disciplines, but it was conventional in five disciplines and it was optional in Mathematics. On the other hand, Move 3, the secondhighest move that occurred, attained obligatory in four disciplines and conventional in the other two disciplines. Meanwhile, the salience of Move 5 was optional across all the disciplines. Even though its appearances were high in the Geography subject with
$85 \%$ of occurrences, more thorough research needs to be conducted along with more data for the corpus to find out the reason for its high number of appearances.

The findings showed that Social Science studies demand a thorough summary of their study by including most of the moves in their abstracts from introduction to findings and discussion (Arsyad, 2019). On the other hand, most of the abstracts of the Natural Science focused on describing the background of the research which were followed by the methodology that was used in the study and the contribution of their studies (Omidian, Shahriari, \& Siyanova-Chanturia, 2018). One of the reasons may be related to the difficulty of the terms used in the Natural Science studies. By highlighting Move 1, the authors of Natural Science studies attempted to avoid the confusion of the terms being used in their studies by presenting the general knowledge of the topic being research. These differences suggest an insight that different disciplines employed different strategies in realizing the moves used in their abstracts.

Regarding the steps, Step 3 of Move 3- Describing procedure and context(s) can be considered obligatory across all the disciplines. Besides, Step 1 of Move 5Deducing conclusion was conventional across all the disciplines. It is also found that both fields applied different strategies in realizing the steps in Move 1. Natural Science focused to develop the Move in Step 2Making topic generalization since it attained conventional status, while Step 4- Identifying gap was the one that attained conventional status that become the main focus for Move 1 in Social Science studies. This finding further strengthens the previous discussion where the authors in Natural Science studies seemed to give more explanation about the topic discussed by their studies. In contrast to Natural Science studies, Social Science studies focused more on explaining the reasons for conducting their studies. Moreover, Step 4 of Move 5- Recommendation had a high level of appearances in Social Science than in Natural Science. By reflecting on the limitation of their research, the authors can provide direction on further research to the readers who are interested in the topic. There were some disciplines that had high occurrences of typical steps (see Table 4.3). However, there is a need to conduct future research with a larger scope of data to assess whether this tendency is applicable in a much larger corpus.

Other than that, the low occurrences of Step $3(58 \%$, $50 \%$, and $71 \%$ ) in Social Science studies did not reflect their obligatory status i.e. $95 \%, 95 \%$, and $100 \%$. Another piece of evidence was also found in Step 1 of Move 5 where Geography and Sociology attained 59\% and $80 \%$ respectively in the occurrences, but both disciplines had $88 \%$ and $60 \%$ appearances where the steps should manifest more in Sociology abstracts rather than in the Geography abstracts if the number of 
occurrences correlated to the number of saliences. Thus, the findings concluded that the number of occurrences does not necessarily reflect the salience of moves and steps.

The high number of abstracts featuring Step 3 of Move 3 and Step 1 of Move 5 indicated that the authors pay great attention to the methodology and the conclusion of the research. Consequently, the readers can easily spot the procedures being employed by the studies and the summary of the contribution of the research. By knowing the salience of each step of each discipline, the authors may have more information when writing their own abstracts which correspond with the norms in their disciplines.

\section{CONCLUSION}

In conclusion, both fields of Natural Science and Social Science studies include all of the moves in their abstracts writing. However, some differences also occur in the realization of the moves. Move 1, Move 3 and Move 4 are the most manifested move that construct the move-based pattern in Natural Science studies. On the other hand, all of the Social Science disciplines incorporate Move 1 to Move 4 in their abstracts. As a result, Social Science studies tend to have a thorough summary of their abstracts while Natural Science focused on highlighting the methodology and findings of the study along with describing background of the research in the beginning. Regarding the steps, the differences arise in Move 1 where Step 2 is conventional in Natural Science while Step 4 is the one that got conventional status in Social Science. Besides, Social Science had more of the manifestation of Step 4 of Move rather than in Natural Science. Moreover, the manifestation of embedded moves and steps in the abstract also imply that disciplinary variations on abstracts affect the way of authors in delivering the information they want to convey in their abstract. These discussions imply that Natural Science and Social Science employ different strategies in the manifestation of move and step. Even though there are some commonalities between both fields, but disciplinary variations do affect the manifestation of all moves and steps.

For future research, authors can explore the disciplinary variation of the abstracts with a larger corpus. The low number of data in this study may be biased in describing certain specific discussion. Thus, author can assess the compatibility of the result of this study in a bigger corpus. Moreover, future studies can also compare the variations between Natural Science and Social Science with different disciplines than the one that were used in this study. Consequently, authors can reveal whether the result of this study is applicable in different disciplines of the same field. It is also recommended for lecturers to teach their students about rhetorical moves since I believe that the findings of this study can help students in writing their abstracts. By understanding the manifestation of moves and steps of each discipline, authors can write an abstract that is corresponding with their disciplines' customs and rules.

\section{REFERENCES}

Adnan, Z. (2009). Some potential problems for research articles written by Indonesian academics when submitted to international English language journals. The Asian EFL Journal Quarterly, 11(107).

Afshar, H. S., Doosti, M., \& Movassagh, H. (2018). A genre analysis of the introduction section of applied linguistics and chemistry research articles. Iranian Journal of Applied Linguistics, 21(1), 163-214.

Anthony, L. (2003). AntMover. Software Retrievable from http://antpc1.ice.ous.ac.jp.

Arsyad, S. (2019). The effect of genre-based mentoring on rhetorical quality of research article drafts by Indonesian lecturers in social sciences and humanities. International Journal of Instruction, 12(3).

Arsyad, S., \& Arono. (2016). Potential problematic rhetorical style transfer from first language to foreign language: A case of Indonesian authors writing research article introductions in English. Journal of Multicultural Discourses, 11(3), 315-330.

Basturkmen, H. (2012). A genre-based investigation of discussion sections of research articles in dentistry and disciplinary variation. Journal of English for Academic Purposes, 11(2), 134-144.

Bhatti, I. A., Mustafa, S., \& Azher, M. (2019). Genre analysis of research article abstract in linguistics and literature: A cross disciplinary study. International Journal of English Linguistics, 9(4).

Cotos, E., Huffman, S., \& Link, S. (2017). A move/step model for methods sections: Demonstrating rigour and credibility. English for Specific Purposes, 46, 90-106.

El-Dakhs, D. A. S. (2018). Comparative genre analysis of research article abstracts in more and less prestigious journals: Linguistics journals in focus. Research in Language, 16(1), 47-63.

Elhambakhsh, S. E., Jalilifar, A., \& White, P. R. (2018). A comparative genre analysis of academic textbook introductions in applied linguistics and medicine. Global Journal of Foreign Language Teaching, 8(3), 112-130. 
ElMalik, A. T., \& Nesi, H. (2008). Publishing research in a second language: The case of Sudanese contributors to international medical journals. Journal of English for Academic Purposes, 7(2), 87-96.

Fatma, K. A. Y. A., \& YAĞIZ, O. (2020). Move analysis of research article abstracts in the field of ELT: A comparative study. Dil ve Dilbilimi Çalışmaları Dergisi, 16(1), 390-404.

Hirano, E. (2009). Research article introductions in English for specific purposes: A comparison between Brazilian Portuguese and English. English for specific purposes, 28(4), 240-250.

Holmes, R. (1997). Genre analysis, and the social sciences: An investigation of the structure of research article discussion sections in three disciplines. English for specific Purposes, 16(4), 321-337.

Hyland, K. (2004). Disciplinary discourses, Michigan classics ed.: Social interactions in academic writing. University of Michigan Press.

Kafes, H. (2012). Cultural traces on the rhetorical organization of research article abstracts. International Journal on New Trends in Education and Their Implications, 3(3), 207-220.

Kanoksilapatham, B. (2005). Rhetorical structure of biochemistry research articles. English for specific purposes, 24(3), 269-292.

Kurniawan, E., Lubis, A. H., Suherdi, D., \& Danuwijaya, A. A. (2019). Rhetorical organization of applied linguistics abstracts: Does scopus journal quartile matter? GEMA Online ${ }^{\circledR}$ Journal of Language Studies, 19(4).

Loi, C. K., \& Evans, M. S. (2010). Cultural differences in the organization of research article introductions from the field of educational psychology: English and Chinese. Journal of Pragmatics, 42(10), 28142825.

Lubis, A. H. (2018). The manifestation of move-step pattern in EFL students' research article: A corpusbased discourse analysis (Doctoral dissertation). Retrieved from http://repository.upi.edu/36845/

Male, H. (2018). A structural move analysis of abstracts in undergraduate theses: A case study at Universitas Kristen Indonesia. KnE Social Sciences, 284-294.

Marefat, H., \& Mohammadzadeh, S. (2013). Genre analysis of literature research article abstracts: A cross-linguistic, cross-cultural study. Applied Research on English Language, 2(2), 37-50. Retrieved from https://www.sid.ir/

Nasseri, D., \& Nematollahi, B. A. B. A. K. (2014). A Contrastive genre analysis of abstract of master of arts (MA) theses in applied linguistics written by native and non-native speakers of English with respects to moves and move markers. Indian J. Sci. Res, 7(1), 1353-1366.

Omidian, T., Shahriari, H., \& Siyanova-Chanturia, A. (2018). A cross-disciplinary investigation of multiword expressions in the moves of research article abstracts. Journal of English for academic purposes, 36, 1-14.

Pasavoravate, Y. (2011). Genre analysis of thesis and dissertation abstracts in linguistics written by students in Thailand and students in England (Doctoral dissertation, Chulalongkorn University).

QS World Ranking University. (2020). Retrieved from https://www.topuniversities.com/universityrankings/world-university-rankings/2020

Ren, H., \& Li, Y. (2011). A comparison study on the rhetorical moves of abstracts in published research articles and master's foreign-language theses. English Language Teaching, 4(1), 162-166.

Dos Santos, M. B. (1996). The textual organization of research paper abstracts in applied linguistics. TextInterdisciplinary Journal for the Study of Discourse, 16(4), 481-500.

Suryani, F. B., \& Rismiyanto, R. (2019). Move analysis of the English bachelor thesis abstracts written by Indonesians. Prominent, 2(2).

Wirada, A. (2012). A comparative study of English applied linguistics research articles between Thai and internationally published journals: Moves and formulaic sequences (Doctoral dissertation, School of English Institute of Social Technology Suranaree University of Technology).

Yakhontova, T. (2006). Cultural and disciplinary variation in academic discourse: The issue of influencing factors. Journal of English for academic purposes, 5(2), 153-167. 